\title{
A field investigation of physical and chemical mechanisms affecting pollutant concentrations in fog droplets
}

\author{
By DANIEL J. JACOB, JED M. WALDMAN, J. WILLIAM MUNGER and \\ MICHAEL R. HOFFMANN, Environmental Engineering Science, W. M. Keck Laboratories, \\ California Institute of Technology, Pasadena, CA 91125, USA
}

(Manuscript received November 8, 1983; in final form February 15. 1984)

\begin{abstract}
High ionic loadings were found in fogwater collected at Bakersfield. California during an extended stagnation episode. The major ions were $\mathrm{NH}_{4}^{+}, \mathrm{NO}_{3}^{-}$, and $\mathrm{SO}_{4}^{2-}$, with concentrations usually in the millimolar range. Droplet growth played an important rôle in determining fogwater concentrations. The amount of solute decreased substantially over the course of each fog event: this was attributed, at least in part, to deposition of fog droplets on surfaces. The occurrence of dense fogs thus seemed to limit particle build-up during stagnation episodes. The sulfate fraction in the aerosol increased appreciably over several days of stagnation, but no statistical evidence for in situ S(IV) aqueous-phase oxidation was found. The high ammonia concentrations present were sufficient to neutralize a large fraction of the ambient acidity. As a result, fogwater $\mathrm{pH}$ values rarely attained the extremely low values found in other polluted environments.
\end{abstract}

\section{Introduction}

Concern about acidic precipitation has stimulated research efforts to understand the chemistry of non-precipitating clouds (Petrenchuk and Drozdova, 1966; Lazrus et al., 1970; Hegg and Hobbs, 1982; Hegg, 1983). Ionic concentrations higher than those found in rain have been observed in clouds and fogs (Munger et al., 1983). In fog, the condensation of water vapor on pre-existent particles in the boundary layer shifts the aerosol size distribution towards larger sizes and produces a dilute aqueous aerosol. These physical and chemical changes in the aerosol may significantly affect its characteristics with regard to air pollution potential and deposition.

Even though fogs have been linked in the past to health-threatening pollution episodes (Commins and Waller, 1967), few field studies of fogwater chemistry have been made. Houghton (1955) sampled fog at several sites in New England and observed high concentrations of components that he attributed to the dissolution of activated nuclei. $\mathrm{He}$ found relatively high acidities and suggested that they were due to the scavenging of free sulfuric acid nuclei. Mrose (1966) and Okita (1968) also found elevated ionic concentrations and acidities in East Germany and Japan, respectively. Mader et al. (1949) reported sulfuric acid aerosol concentrations as high as $150 \mu \mathrm{g} \mathrm{m}^{-3}$ during fog events in Los Angeles. These values were comparable to those observed during some London fogs (Goodeve, 1936). Waldman et al. (1982) and Munger et al. (1983) found extremely high ionic concentrations in Los Angeles area fogwater; solute concentrations were in the millimolar range for the major components, and $\mathrm{pH}$ values were usually in the range of 2 to 4 .

Fog droplets appear to be efficient scavengers of boundary layer pollutants, and could provide a favorable environment for aqueous-phase reactions leading to the production of strong acids (Jacob and Hoffmann, 1983). The oxidation of absorbed S(IV) to form S(VI), with the concomitant production of acidity, is suspected as being an important reaction in the aqueous phase. Cass (1979) has observed that the worst sulfate pollution episodes in Los Angeles occur during periods of high 
humidities and coastal fog, and Hegg and Hobbs (1982) have reported $\mathrm{SO}_{2}$ conversion rates of up to $1900 \% \mathrm{~h}^{-1}$ in clouds. Laboratory studies (Martin, 1984) indicate that the oxidation of S(IV) can proceed rapidly at atmospheric concentrations in the presence of strong oxidants.

This paper presents results of a field investigation of fogwater composition in the southern San Joaquin Valley of California. The San Joaquin Valley is a site of both agricultural activity and oil recovery operations, which lead to high atmospheric loadings of particulate matter and trace gases. Fogs are common in the Valley during the winter months and can form every night under near-stagnant conditions caused by mesoscale subsidence. Because of the unusual stability in the local weather pattern and air masses, as well as the identification of emission sources (California Air Resources Board (CARB), 1982), it was possible to study the physical and chemical parameters influencing the fogwater composition, and to evaluate the cumulative effect of repeated fog occurrences on the chemical loading of an air mass.

\section{Site description and measurement techniques}

\subsection{Site description}

All measurements were made at Bakersfield (Kern county) from 30 December 1982 to 15 January 1983. Kern county is located at the southern tip of the Central Valley of California, which extends north about $700 \mathrm{~km}$. The Valley is approximately $80 \mathrm{~km}$ wide over its entire length and is encompassed by mountain ranges (Fig. 1). Apart from a narrow gap at the Sacramento river delta, egress from the Valley is possible only through mountain passes. The lowest passes to the east and south are above $1000 \mathrm{~m}$ elevation. The Valley is subdivided into the San Joaquin and Sacramento Valleys, south and north of the Sacramento gap respectively. In the southern part of the San Joaquin Valley the lowest pass to the west is at $600 \mathrm{~m}$ elevation.

The wintertime meteorology of the Central Valley is dominated by the Basin High, which creates a very strong subsidence inversion (Holets and Swanson, 1981). The base of the inversion is typically $200 \mathrm{~m}$ to $500 \mathrm{~m}$ above ground level (AGL), although it occasionally comes down to the

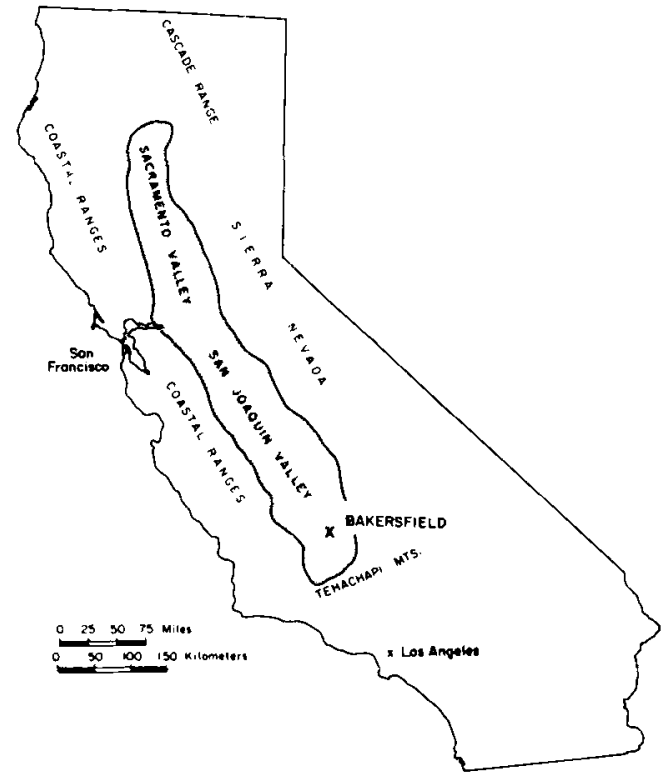

Fig. 1. The Central Valley of California.

ground. This stable synoptic pattern is interrupted periodically by a frontal passage which often leads to precipitation on the Valley floor. As the subsidence resumes, the moist air is trapped inside the Valley. Loss of heat by radiation eventually leads to the formation of a widespread fog layer. Under these conditions, fog (locally called "Tule" fog) can form nightly and last into the late morning, with a persistent haze lasting through the afternoon.

Because the mixing height is usually lower than the natural boundaries of the Valley, the transport of air masses in and out of the Valley during these episodes is very limited. A weak net flow north out of the San Joaquin Valley leads to a residence time of 8 to 12 days for an air mass in the San Joaquin Valley (Reible et al., 1984). The daytime up-slope flow and the night-time drainage flow associated with the heating and cooling of the mountain slopes dominate the wind patterns in the Valley itself. Flow divergence from the Valley floor in the day, and convergence at night, has been observed by Smith et al. (1981). In the winter, because of the reduced insolation, this flow is probably too weak to ventilate the Valley by transport over the mountain ridges (Reible et al., 1983). As a result, between frontal passages and the ensuing at- 
mospheric cleansing, the air in the Valley is near-stagnant.

Major oil fields are located in Kern county, and large amounts of $\mathrm{SO}_{2}$ and $\mathrm{NO}_{x}$ are released in the steam-injection oil recovery operations (CARB, 1982). In addition, most of the Valley floor is occupied by farming and ranching activities, which are important sources of primary particulate matter (CARB, 1982) and ammonia. At the high humidities prevalent in the winter months, primary and secondary $\mathrm{H}_{2} \mathrm{SO}_{4}$ and $\mathrm{HNO}_{3}$ react with $\mathrm{NH}_{3}$ and $\mathrm{H}_{2} \mathrm{O}$ to form ammonium sulfate and nitrate droplets (Stelson, 1982). Because of the production of this secondary aerosol, Kern county experiences severe sulfate pollution episodes in the winter months (Duckworth and Crowe, 1979).

\subsection{Measurement techniques}

Fog and aerosol samples were collected from the roof of a three-story building in downtown Bakersfield, above a CARB air monitoring station. The surroundings are residential and commercial, with no major point pollutant sources. There are no nearby structures taller than the site. An east-west highway, with usually moderate traffic, is located $500 \mathrm{~m}$ south of the site.

Fogwater was sampled with a rotating arm collector, which has been characterized in detail elsewhere (Jacob et al., 1984). This instrument samples air at a rate of $5 \mathrm{~m}^{3} \mathrm{~min}^{-1}$, performs well in preserving the chemical integrity of the sample at all stages of collection, and has a lower size cut of $20 \mu \mathrm{m}$ diameter (determined by experimental calibration). Jacob et al. (1984) have estimated that on the average, $60 \%$ of the total liquid water is collected with this device. Fogwater samples were collected over periods ranging from $30 \mathrm{~min}$ to $3 \mathrm{~h}$, and were analyzed for major ions, trace metals, S(IV), formaldehyde, and total organic carbon. Sample handling and analytical procedures were identical to those described previously (Munger et al., 1983).

Aerosol between fog events was collected on a set of two Gelman Zefluor Teflon filters. One filter, which was surmounted by a cap to prevent preferential sampling of large particles by sedimentation, was open-faced and collected total particulate matter; the other was set downstream of a cyclone separator which removed particles larger than $2 \mu \mathrm{m}$. After $11 \mathrm{January}$, only the open-faced filter was used. Filter samples were taken over time intervals ranging from 2.5 to $8 \mathrm{~h}$. The filters were extracted in $10 \mathrm{ml}$ of water on a reciprocating shaker for $60 \mathrm{~min}$, and analyzed for major ions using the same analytical methods as for the fogwater.

Gaseous ammonia was collected by absorption on an oxalic acid impregnated Gelman glass fiber filter set downstream of the open-faced Teflon filter. Ammonium ion was determined by the phenolhypochlorite method on a water extract using a modification described by Russell (1983).

Liquid water content was measured by drawing air at a rate of $1 \mathrm{~m}^{3} \mathrm{~min}^{-1}$ through open-faced paper filters. The filters were exposed to the fog prior to use to equilibrate them with the ambient humidity. The liquid water content was determined by weight. This method has been found (Calspan Corp., Buffalo, NY, private communication) to yield results comparable to those obtained with more sophisticated optical methods (Chylek, 1978). It must be stressed that no fully reliable method for measuring absolute liquid water content exists to date, and that variations in results of up to $50 \%$ commonly occur from one method to another; therefore measurements must be interpreted with caution.

The CARB air monitoring station located at the site provided hourly averages of gas-phase NO, $\mathrm{NO}_{x}, \mathrm{SO}_{2}, \mathrm{O}_{3}$, and $\mathrm{CO}$ concentrations. Hourly mixing height measurements (from $30 \mathrm{~m}$ up to $1000 \mathrm{~m}$ ) were obtained at Bakersfield by acoustic sounding (Western Oil and Gas Association, Los Angeles, private communication). Hourly weather observations were recorded $8 \mathrm{~km}$ north of our site by the Bakersfield National Weather Service office (National Oceanic and Atmospheric Administration, 1983).

\subsection{Weather pattern}

On 22-23 December, a frontal passage over the Valley deposited $7.6 \mathrm{~mm}$ of rain on Bakersfield. A strong subsidence associated with the Basin High followed, and a stratus deck started forming on 26 December. Temperatures dropped and were 3 to $7^{\circ} \mathrm{C}$ lower than normal during the period 30 December-15 January. Daily highs ranged from 4 to $8^{\circ} \mathrm{C}$ and daily lows from -2 to $3{ }^{\circ} \mathrm{C}$. Fog was reported at the Bakersfield site on 29 and 30 December, but was patchy in the surrounding area. In the text, the date of the fog will be given as that of the morning on which it occurred, even though it 
may have already been formed the previous evening. On 31 December and 1 January, dense widespread fogs persisted through the night and well into the morning. The following three days, 2-4 January, thin radiation fogs formed at the site for a brief period in the early morning as the temperature dropped sharply. Dense widespread fog through the night again occurred on 5 January (not sampled) and on 6-8 January. On 9-10 January, a weak front passed through the Valley, resulting in some clear sunshine, high cloudiness, and drizzle in the morning of 9 January which deposited a trace amount of rain. On the morning of 10 January, a drop in temperature down to $-2{ }^{\circ} \mathrm{C}$ at the site caused the formation of a thin, shallow fog which lasted for $3 \mathrm{~h}$. After 1600 on 10 January, the subsidence inversion again limited the mixing heights to less than $500 \mathrm{~m} \mathrm{AGL}$ and dense, all-night fogs formed every night from 11 January to 15 January. Sampling was discontinued after 15 January. All fogs were sampled from beginning to end, except the 31 December and 11 January fogs, for which sampling did not start until a few hours after fog formation.

\section{Results and discussion}

\subsection{Fogwater concentrations}

Table 1 gives the range and median value of fogwater concentrations for the entire data set $(n=108)$. Close ionic balances for most fogwater samples $( \pm 10 \%$ in over $80 \%$ of the cases) indicate that no important jons were missed in analysis. Ammonium, nitrate, and sulfate ions, by far the most important components present, had concentrations usually in the millimolar range. These high concentrations indicate the dominant impact of agriculture $\left(\mathrm{NH}_{4}^{+}\right)$and fuel combustion $\left(\mathrm{NO}_{3}^{-}\right.$, $\mathrm{SO}_{4}^{2-}$ ) on the fogwater composition. Occasionally, $\mathrm{H}^{+}, \mathrm{Ca}^{2+}$, and $\mathrm{Cl}^{-}$contributed significantly to the total equivalent loading of the droplets. Ratios of concentrations of $\mathrm{Na}^{+}$to other ions indicated that sea salt was not a major source. Iron and lead were the most prominent trace metals.

Fig. 2 shows the evolution of fogwater concentrations with time during the 7 January fog. Winds were light and variable throughout the night, and temperatures ranged from 1 to $3^{\circ} \mathrm{C}$. As droplets grew at the beginning of the fog, they

Table 1. Fogwater concentrations at Bakersfield, California*

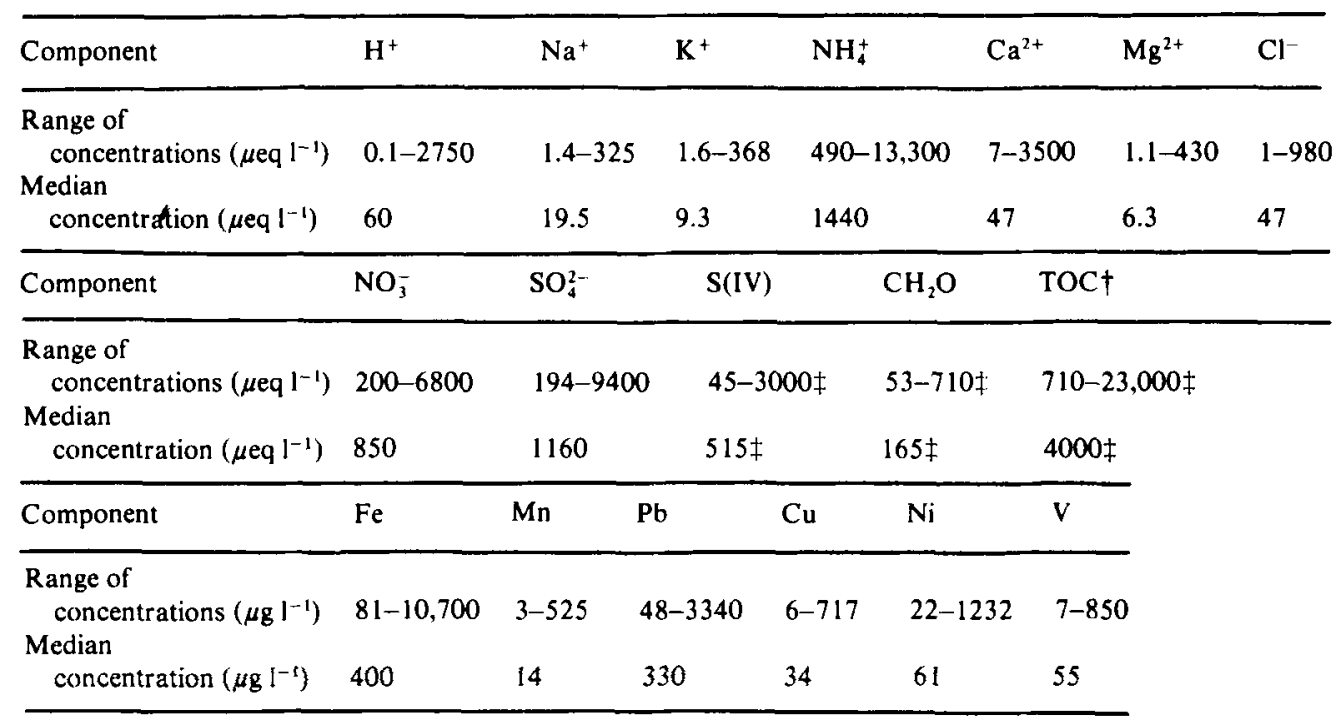

(a) Hydroxymethanesufonate ion coelutes with nitrate in the ion chromatographic column, so that nitrate concentrations could be overestimated.

* 108 samples over the period 30 December 1982-15 January 1983.

$\dagger$ Total organic carbon.

$\ddagger$ For S(IV), $\mathrm{CH}_{2} \mathrm{O}$, and total organic carbon, concentrations are in $\mu$ moles $\mathrm{I}^{-1}$.

Tellus 36B (1984), 4 


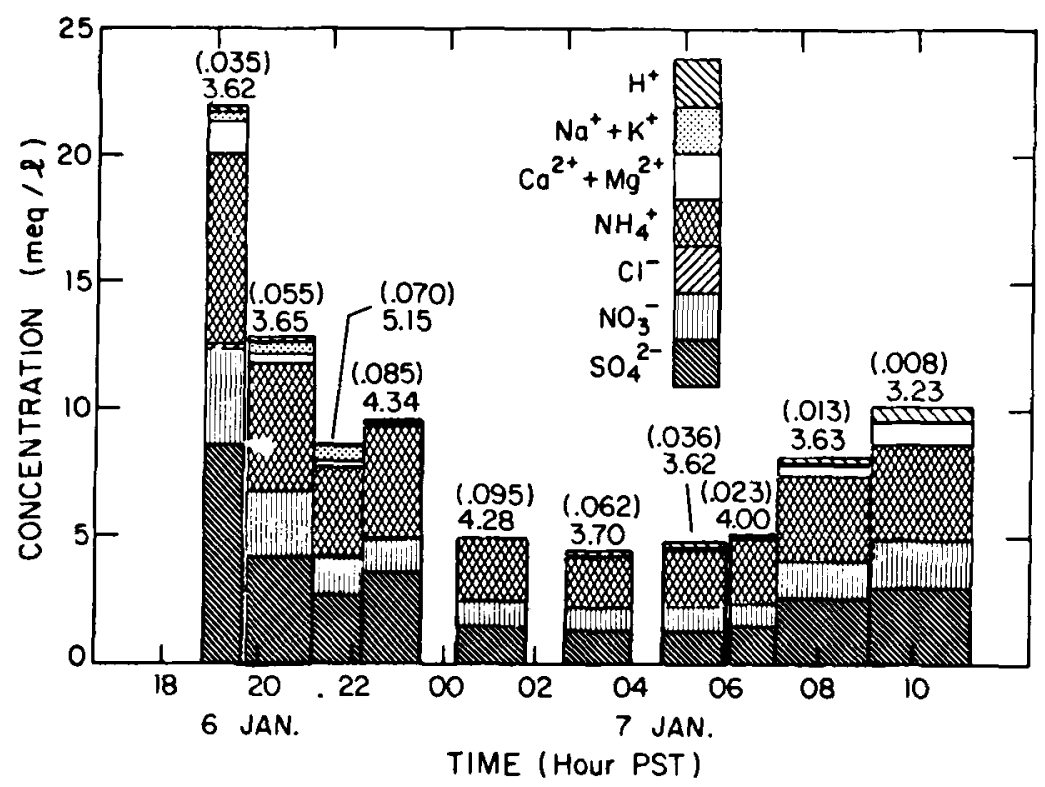

Fig. 2. Evolution of fogwater concentrations over the course of the 7 January 1983 fog event at Bakersfield. Fogwater $\mathrm{pH}$ and average liquid water contents ( $\mathrm{g} \mathrm{m}^{-3}$, in parentheses) are indicated on top of each data bar.

became more dilute, and conversely as the fog dissipated, evaporation concentrated the droplets. The resulting concave profile for fogwater concentrations was evident in all the events sampled over the course of this investigation, and has been found to be a characteristic of fogs in other locations as well (Waldman et al., 1982). Droplet growth is therefore a dominant process in controlling fogwater concentrations. Accordingly, acidities were usually the highest at the beginning and end of fog events. The ratio of concentrations of one component to another was not subject to large variations from sample to sample within one event, which implies that the air masses were generally homogeneous. A trend of decreasing concentrations, superimposed on the concave profile, was noted. We will see that this can be attributed, at least in part, to deposition of fog droplets on surfaces.

\subsection{Atmospheric particulate loadings in relation to fog occurrences}

The major components of the daytime aerosol were $\mathrm{NO}_{3}^{-}, \mathrm{SO}_{4}^{2-}$, and $\mathrm{NH}_{4}^{+}$. No significant differences were observed between the total aerosol and fine aerosol filters for $\mathrm{NH}_{4}^{+}, \mathrm{NO}_{3}^{-}, \mathrm{SO}_{4}^{2-}$, and
$\mathrm{Cl}^{-}$concentrations. On the other hand, concentrations of $\mathrm{Na}^{+}, \mathrm{Ca}^{2+}$, and $\mathrm{Mg}^{2+}$ were higher in the total aerosol than in the fine aerosol; coarse soil dust is probably a major source of these components. Fig. 3 summarizes the evolution of atmospheric loadings over the 17-day sampling period. Mixing height data and concentrations of trace gases are given as hourly averages. Ozone concentrations were at or below the detection limit of $10 \mathrm{ppb}$ in $96 \%$ of the hourly measurements. Time-averaged fogwater loadings $/ \mathrm{m}^{3}$ of air (calculated from liquid water content measurements) are given for each fog event, along with the aerosol loadings and gaseous ammonia concentrations between fog events. Prior to 6 January, the liquid water content was not directly measured; we estimated it by measuring the amount of water collected and assuming a $60 \%$ collection efficiency. In our calculations of the fogwater loadings, we assume that the collected samples are representative of the ambient fogwater in spite of the high lower size-cut of the sampler. The individual contributions of droplets of different sizes to the overall fogwater loading have not yet been rigorously investigated; they are difficult to predict from droplet growth theory (Pruppacher and Klett, 


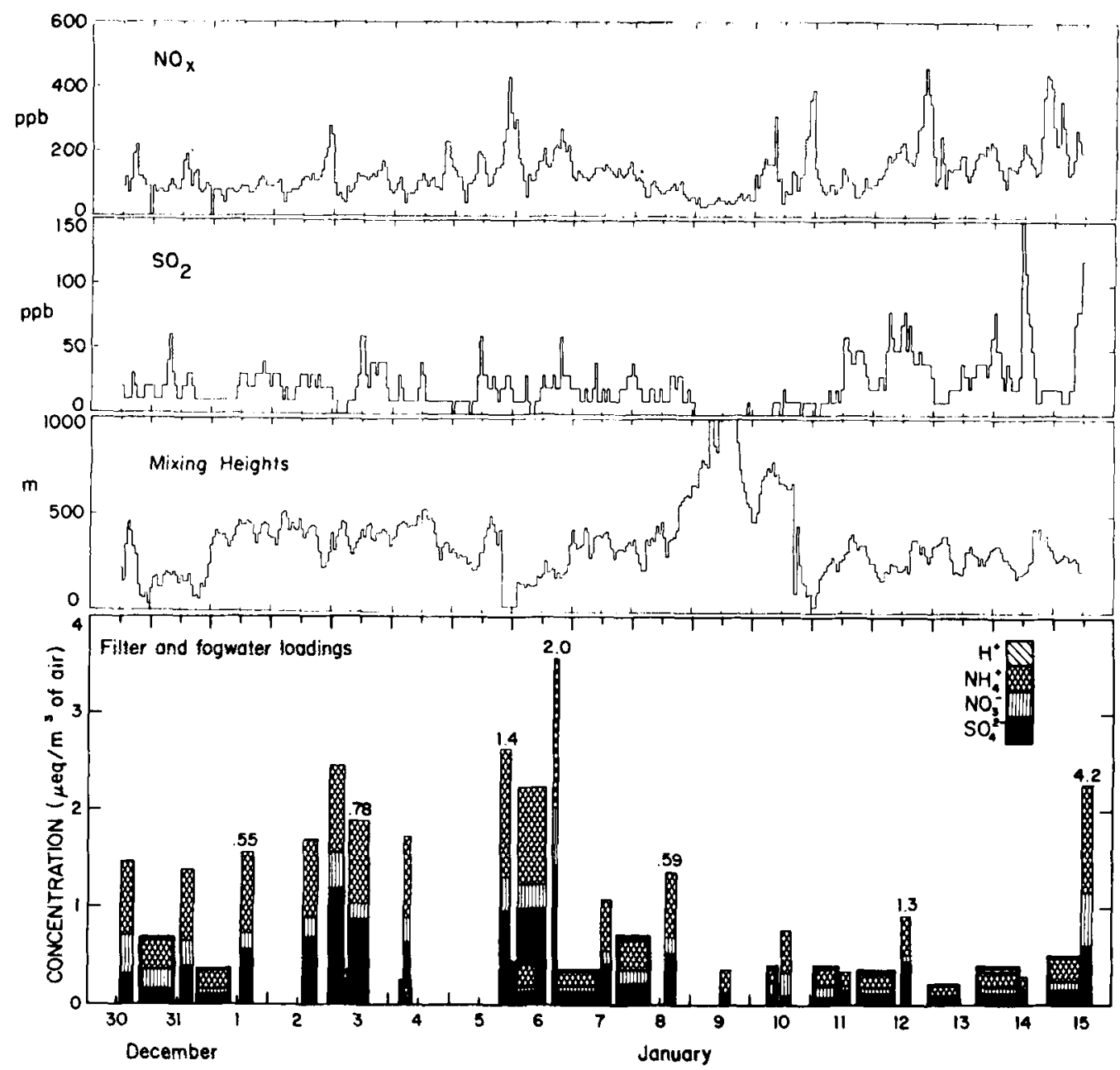

Fig. 3. Fogwater (in bold) and aerosol loadings of $\mathrm{NH}_{4}^{+}, \mathrm{NO}_{3}^{-}, \mathrm{SO}_{4}^{2-}$ and $\mathrm{H}^{+}$(fogwater) measured at Bakersfield during the period 30 December 1982-15 January 1983. When measured, gaseous ammonia concentrations (p.p.b.: 1 p.p.b. $=0.044 \mu$ moles $\mathrm{m}^{-3}$ at $1^{\circ} \mathrm{C}$ ) are indicated on top of the aerosol data bars. Mixing heights are given in $(\mathrm{m})$ above ground level.

1978) because supersaturations in fogs fluctuate rapidly in a poorly understood manner (Roach. 1976; Gerber, 1981). The large droplets in the fog are likely to have condensed on large nuclei, and therefore are not necessarily more dilute than the smaller droplets. A recent field intercomparison study of fogwater sampling devices (Hering and Blumenthal, 1983) seems to indicate that variations in the composition of the fogwater collected by instruments with different droplet size-cuts are insignificant.

The mixing height data show that two distinct air masses were involved during the 17-day period. The base of the inversion layer usually oscillated between $100 \mathrm{~m}$ and $500 \mathrm{~m}$ AGL. However, on 9 January, the inversion layer rose to above $1000 \mathrm{~m}$ and possibly vanished (no measurements were available above $1000 \mathrm{~m}$ ). This allowed mixing with air from outside the Valley, and, with the added contribution of the 9 January morning drizzle. effectively renewed the air mass in the Valley. After the afternoon of 10 January, stagnation conditions resumed and no mixing heights above $500 \mathrm{~m}$ were recorded until after 15 January. 
Aerosol and trace gas loadings reflected the apparent change in air masses. Since emission sources are located close to the ground, the majority of pollutants were released below the base of the inversion layer. Due to the lack of ventilation, accumulation of pollutants proceeded. During the period of 30 December to 9 January, the stagnant air mass was well-aged; high particulate and $\mathrm{SO}_{2}$ levels were observed. After the effective cleansing of the atmosphere on 9-10 January, aerosol and $\mathrm{SO}_{2}$ loadings dropped sharply.

On several occasions, aerosol samples were taken a few hours before a fog formation. The fraction of the afternoon aerosol found in the first fogwater sample collected the following night ranged from 0.1 to 0.8 and from 0.2 to 2.0 for sulfate and nitrate, respectively. These numbers varied considerably from fog to fog, and this can be attributed to variations in nucleation scavenging efficiencies and differences in the air masses advected over the site in the afternoon and at night. It is therefore not possible to make quantitative conclusions with regard to aerosol scavenging efficiencies, but it appears that a substantial fraction of the aerosol is incorporated into the fog droplets.

Scavenging of trace gases is an additional source of chemical input to the fogwater. The solubility of several gases in fog droplets has been discussed by Jacob and Hoffmann (1983). Nitric acid is $100 \%$ scavenged, and so is ammonia below pH 5. From the gas phase data, it appears that the occurrence of fog does not by itself affect partial pressures of $\mathrm{SO}_{2}$; thermodynamic considerations indicate that, in spite of the dissociation of $\mathrm{SO}_{2} \cdot \mathrm{H}_{2} \mathrm{O}$ in solution and the formation of S(IV) adducts, absorption of $\mathrm{SO}_{2}(\mathrm{~g})$ by fog droplets is limited to a few \% because of the small amount of water present. No correlation appears either between $\mathrm{NO}_{\mathrm{x}}$ levels and fog occurrences. This agrees with the results of Schwartz and White (1981), who show that the dissolution of $\mathrm{NO}_{x}$ at atmospheric concentrations is too slow to be of relevance over the lifetime of the fog.

All the extended fog events sampled over the 17-day period showed a substantial decrease in the fogwater loadings over the course of the fog (Fig. 4). Loadings of major ions at the end of the fog ranged from $4 \%$ to $36 \%$ (median $17 \%$ ) of those at the beginning of the fog, depending on the event. However, the steady decreasing pattern was not established until a few hours after fog formation; in the initial stage of the fog, the evolution of fogwater loadings was irregular. Changes in the fogwater loadings over the course of the fog could be

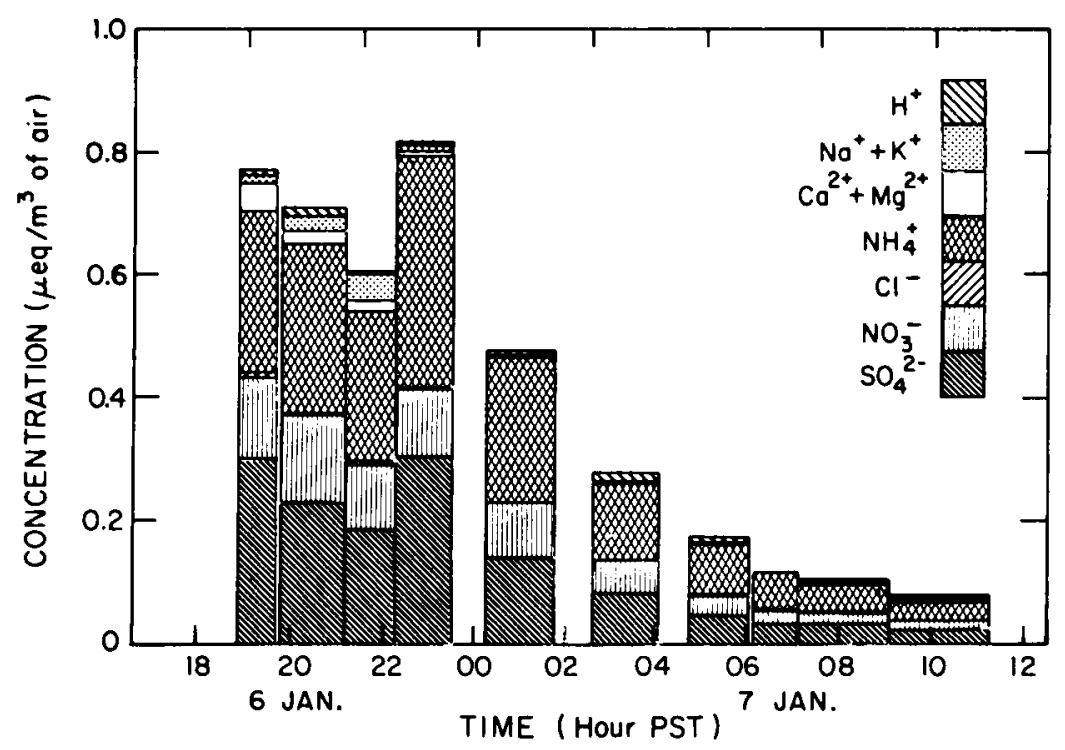

Fig. 4. Evolution of fogwater ionic loadings over the course of the 7 January fog event. 
attributed to deposition of the coarse fog droplets, short-range transport, or displacement of the inversion base. Comparison of daytime aerosol or nighttime fog loadings to the mixing heights over the same time period did not show any strong correlation for mixing heights below $600 \mathrm{~m}$. In addition, oscillations of the mixing height over the course of the fogs did not show a consistent trend which could be associated with a decrease in fogwater loadings. Therefore, this factor is probably not critical. Characterization of short-range transport at night is made difficult by the complex drainage flows converging to the center of the Valley. Because Bakersfield is located in the convergence zone, local winds oscillate considerably from hour to hour in both direction and speed (National Oceanic and Atmospheric Administration, 1983). Concentrations of $\mathrm{CO}, \mathrm{NO}_{x}$, and $\mathrm{SO}_{2}$ during fog events did not show the strong decreases that would be associated with the advection of much cleaner air masses over the site. Therefore, it is unlikely that short-range transport could fully account for the considerable decrease of fogwater loadings with time.

Deposition of fog droplets on surfaces, on the other hand, could lead to the observed decreases in fogwater loading. Fog formation results in an important shift of the aerosol distribution towards larger particle sizes; because the residence time in the atmosphere of particles above $10 \mu \mathrm{m}$ is of the order of hours, and rapidly decreases with increasing size (Muller, 1982), the deposition rate of the aerosol must be enhanced. During the early stage of the fog, the droplets presumably do not grow to a size large enough to be effectively deposited; factors other than deposition influence the fogwater loading, and hence the irregular behaviour of the profile of fogwater loadings with time. As a population of "large droplets is later established, deposition becomes more rapid and overcomes other factors. Turbulent diffusion to the ground, impaction and sedimentation are probably all important in contributing to the removal of fog droplets. The numerical study of Brown and Roach (1976) has shown that important droplet settling must occur to explain the low liquid water content observed in fogs; Brown (1980) finds that the settling process does not become important until a few hours after fog formation, which is consistent with our observations. If scavenging of gases and particles by the droplets is followed by deposition, pollutants will effectively be removed from the atmosphere.

Particle concentrations in the Valley are determined by sources (fresh input of primary and secondary aerosol), sinks (transport aloft and out of the Valley, deposition), and intra-Valley transport. Under stagnant conditions, one would expect a pollutant build-up until a steady state is reached due to an eventual balance of sources and sinks. The characteristic time for deposition of haze particles $(0.05-2 \mu \mathrm{m})$ is 3-6 days (Muller, 1982), but under fog conditions, particles scavenged by the fog droplets will deposit much more quickly. Dense fogs can therefore limit particle accumulation. The overall higher loadings during the 26 December -8 January stagnation episode (where dense fog did not form every night) compared to those during the 10 January-15 January episode (where dense fog formed every night) could then be explained by a pollutant build-up due to the predominance of haze but limited fog. This accumulation is obvious for ammonium nitrate and sulfate salts, which are the main constituents of the haze aerosol; on the other hand, concentrations of $\mathrm{Ca}^{2+}$ in the aerosol did not increase during the stagnation episodes. Calcium mostly originates from coarse dust particles with a residence time shorter than one day, and will settle out regardless of fog formation.

\subsection{Heterogeneous $S(I V)$ oxidation}

Because of the high $\mathrm{SO}_{2}(\mathrm{~g})$ concentrations in Bakersfield and the presence of an aquated aerosol, there is a potential for aqueous-phase oxidation of $\mathrm{S}(\mathrm{IV})$ to $\mathrm{S}(\mathrm{VI})$ by the strong oxidants $\mathrm{H}_{2} \mathrm{O}_{2}, \mathrm{O}_{3}$, and $\mathrm{O}_{2}$ (Jacob and Hoffmann, 1983; Martin, 1984). Evolution of sulfate concentrations in the fogwater between times $t_{1}$ and $t_{2}$ can be expressed by:

$$
\begin{aligned}
& {\left[\mathrm{S}(\mathrm{VI})_{t_{2}} \mathrm{~L}\left(t_{2}\right)=\left\{[\mathrm{S}(\mathrm{VI})]_{t_{1}} L\left(t_{1}\right)\right.\right.} \\
& \left.\quad+\int_{t_{1}}^{t_{2}} \frac{\mathrm{d}[\mathrm{S}(\mathrm{VI})]}{\mathrm{d} t} L(t) \mathrm{d} t\right\}(1-r),
\end{aligned}
$$

where $L(t)$ is the liquid water content of the fog, and $r$ characterizes changes in $[\mathrm{S}(\mathrm{VI})]$ (assumed first-order) due to physical mechanisms such as deposition. We assume as a first approximation that $L(t)$ and $r$ control the evolution of the chemically conservative quantity $[T]$, defined as the sum of the equivalent concentrations of all 
components $A_{i}$ in solution minus sulfate and its counter-ion:

$|T|=\sum_{i=1}^{n}\left[A_{i}\right] .-2|\mathrm{~S}(\mathrm{VI})|$

With this assumption, we can write for a homogeneous air mass:

$[T]_{t_{2}} L\left(t_{2}\right)=[T]_{t_{1}} L\left(t_{1}\right)(1-r)$,

and substitute (3) into (1):

$$
\begin{aligned}
& \int_{t_{1}}^{t_{2}} \frac{\mathrm{d}[\mathrm{S}(\mathrm{VI})]}{\mathrm{d} t} L(t) \mathrm{d} t=L\left(t_{1}\right)\left([\mathrm{S}(\mathrm{VI})]_{t_{2}}\right. \\
& \left.\times \frac{[T]_{t_{1}}}{[T]_{t_{2}}}-[\mathrm{S}(\mathrm{VI})]_{t_{1}}\right) .
\end{aligned}
$$

A major difficulty in solving (4) for $\mathrm{d}[\mathrm{S}(\mathrm{VI})] / \mathrm{d} t$ and using statistical analysis to verify or derive a rate law is that the variables on which $d[S(V I)] / d t$ depends are not satisfactorily quantified. Reactions of S(IV) with $\mathrm{H}_{2} \mathrm{O}_{2}$ and $\mathrm{O}_{3}$ are expected to be first-order in oxidant concentrations (Martin, 1984), but $\mathrm{H}_{2} \mathrm{O}_{2}$ and $\mathrm{O}_{3}$ concentrations were not measured at Bakersfield (ozone below the detection limit of $10 \mathrm{ppb}$, as observed, still cannot be neglected as an oxidant in droplets with high $\mathrm{pH}$ ). Oxygen has been predicted to be an effective oxidant in solution when catalyzed by trace metals (Jacob and Hoffmann, 1983), but the form of the rate law has not been satisfactorily established at the $\mathrm{pH}$ and free $\mathrm{S}(\mathrm{IV})$ concentration ranges typical of the Bakersfield fogwater (Martin, 1984); furthermore, it may be complicated because of aqueousphase speciation of metals and S(IV) (Hoffmann and Jacob, 1984).

Rates of sulfate production in the atmosphere have previously been derived from field data by Cass (1981) and Hegg and Hobbs (1981, 1982). These investigators expressed this rate in terms of a pseudo first-order rate constant $k\left(\% h^{-1}\right)$ referenced to gas-phase $\mathrm{SO}_{2}$ :

$\frac{\mathrm{d}[\mathrm{S}(\mathrm{VI})]_{\mathrm{air}}}{\mathrm{d} t}=\frac{k}{100}\left[\mathrm{SO}_{2}(\mathrm{~g})\right]$,

where $[\mathrm{S}(\mathrm{VI})\}_{\mathrm{air}}$ and $\left[\mathrm{SO}_{2}(\mathrm{~g})\right]$ are concentrations per unit volume of air. Eq. (5) is obviously unjustified from a chemical standpoint, because it ignores the rate dependence on droplet $\mathrm{pH}$, concentrations of oxidants and catalysts, tem- perature, and photochemical activity. Still, it provides a convenient parameterization of sulfate production and will be adopted here in the absence of a more reliable expression. Substituting (5) into (4):

$$
\begin{aligned}
& \int_{t_{1}}^{t_{2}} \frac{k}{100}\left[\mathrm{SO}_{2}(\mathrm{~g})\right] \mathrm{d} t \\
& \quad=L\left(t_{1}\right)\left([\mathrm{S}(\mathrm{VI})]_{t_{2}} \frac{[T]_{t_{1}}}{[T]_{t}}-[\mathrm{S}(\mathrm{VI})]_{t_{1}}\right) .
\end{aligned}
$$

Assuming that $\left|\mathrm{SO}_{2}(\mathrm{~g})\right|$ varies linearly with time over the interval considered:

$$
\begin{aligned}
k= & \frac{200}{t_{2}-t_{1}} \frac{L\left(t_{1}\right)}{\left[\mathrm{SO}_{2}(\mathrm{~g})\right]_{t:}+\left[\mathrm{SO}_{2}(\mathrm{~g})\right]_{t_{1}}} \\
& \times\left([\mathrm{S}(\mathrm{VI})]_{t_{2}} \frac{[T]_{t_{1}}}{[T]_{t_{2}}}-[\mathrm{S}(\mathrm{VI})]_{t_{1}}\right)
\end{aligned}
$$

Table 2 shows that the $k$ values calculated from our data set with eq. (7) are lower than those obtained by Hegg and Hobbs $(1981,1982)$ for clouds over western Washington State, and are of the order of those observed in the Los Angeles aerosol by Cass (1981). However, both ozone concentrations and $\mathrm{pH}$ were higher in the clouds sampled by Hegg and Hobbs $(1981,1982)$ than in the Bakersfield fogs sampled in this study; in the same way, temperature, solar irradiation, and oxidant concentrations are all lower in Bakersfield (in the wintertime) than in Los Angeles. Therefore, comparison of the data sets in terms of $k$ is difficult.

Cass (1981) noted that gas phase oxidation could not be sufficiently rapid to explain the S(IV) conversion rates in Los Angeles, and suggested aqueous-phase oxidation as an alternate mechanism. Hegg and Hobbs (1982) pointed to S(VI) incloud production from some basic statistical analysis of their data, a conclusion which has been disputed by Schwartz and Newman (Schwartz et al., 1983). Our data set does not allow us to conclude that $k$ is significantly different from zero. Fig. 5 shows the frequency distribution we observed for $k$; the near symmetrical devjations about $k=0 \% \mathrm{~h}^{-1}$ can be simply attributed to the non-Lagrangian nature of the sampling procedure. The presence of a few outliers on the positive side of the distribution could suggest that $S(I V)$ in-fog oxidation proceeds under certain conditions, but these points are associated with $\mathrm{SO}_{2}$ 
Table 2. $\mathrm{SO}_{2}$ oxidation rates in the atmosphere

\begin{tabular}{lll}
\hline Location & $k\left(\% h^{-1}\right)^{*}$ & Reference \\
\hline Western Washington (wave clouds) & $0-300$ & Hegg and Hobbs (1981) \\
Western Washington (clouds) & $-600 \pm 1000-1900 \pm 1900$ & Hegg and Hobbs (1982) \\
Los Angeles (aerosol, summer) & $6.0 \dagger$ & Cass (1981) \\
Los Angeles (aerosol, winter) & $2.0 \dagger$ & Cass (1981) \\
Bakersfield (fogs) & $0.9 \pm 5.5 \ddagger$ & This study \\
\hline
\end{tabular}

- $k$ is a pseudo first-order rate constant expressing sulfate production as a $\%$ of $\left|\mathrm{SO}_{2}(\mathrm{~g})\right|$.

$\dagger$ Hourly production rates averaged over 3 years.

$¥$ Calculated from one fog sample to the next using equation (7). Data for $n=80$ samples. Samples were excluded from the data set when: (i) $\mathrm{SO}_{2}$ partial pressure was below the detection limit of $10 \mathrm{ppb}$; (ii) ionic balances were off by over $30 \%$; or (iii) only one sample was collected during the event ( 2 January).

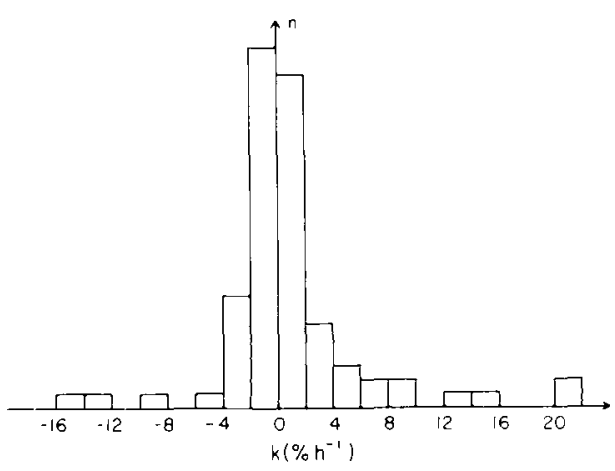

Fig. 5. Frequency distribution of the pseudo first-order rate constant for $\mathrm{S}(\mathrm{VI})$ in-fog production, $k\left(\% h^{-1}\right)$. Data from $n=80$ fogwater samples collected at Bakersfield during the period 30 December 1982-15 January 1983.

concentrations at, or close to, the detection limit of $10 \mathrm{ppb}$. The uncertainty on $\left[\mathrm{SO}_{2}(\mathrm{~g})\right]$ can then be as great as $50 \%$, so that these outliers cannot be considered significantly different from the population as a whole.

Sulfate production was also analyzed in terms of $k / L$, which characterizes sulfate production referenced to the aqueous phase, and in terms of a zero-order dependence on $\left[\mathrm{SO}_{2}(\mathrm{~g})\right]$ (oxidation limited by mass transfer). Neither of these analyses showed evidence of $\mathrm{S}(\mathrm{VI})$ in-fog production.

In spite of this, the sulfate fraction of the aerosol increased over the course of the stagnation episodes (Fig. 6). After the two widespread fogs and

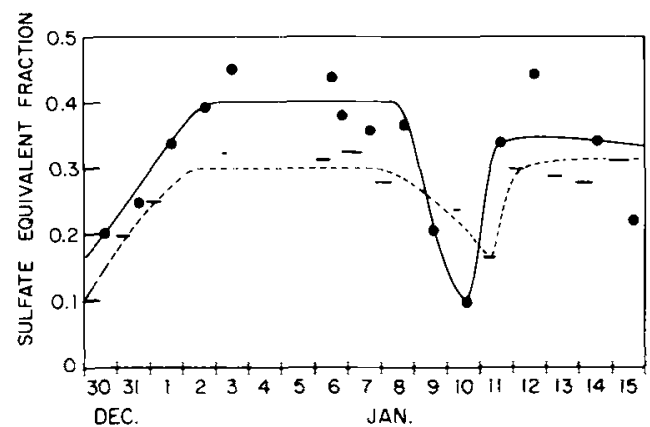

Fig. 6. Evolution of the sulfate equivalent fraction in the fogwater (-) and in the aerosol (O) at Bakersfield during the period 30 December 1982-15 January 1983. Lines have been added to show trends.

persistent thick haze of 31 December and 1 January, the sulfate equivalent fraction (SEF) of the aerosol (defined as SEF $=[\mathrm{S}(\mathrm{VI})] /[T]$ ) rose and stabilized at $0.40 \pm 0.05$. In comparison, the two-month aerosol averages reported by Heisler and Baskett (1981) for November-December 1978 at Bakersfield show an SEF of 0.22. The highest sulfate concentration we observed, $76 \mu \mathrm{g} \mathrm{m}^{-3}$ on 6 January, is close to the highest $24-\mathrm{h}$ value recorded in the area, $80 \mu \mathrm{g} \mathrm{m}^{-3}$ (Duckworth and Crowe, 1979). On 9-10 January, along with the removal of the stagnant air mass from the Valley, the SEF dropped sharply, down to 0.10 on the afternoon of 10 January. After the inversion trapped the renewed air mass in the Valley, the SEF rose again to values similar to those before 10 January. The SEF values for the fogwater were lower than those 
for the afternoon haze, but behaved qualitatively in the same way.

Preferential deposition of components other than sulfate would result in an increase in the sulfate content at the beginning of the stagnation episode. Because nitrate does not show the increase observed for sulfate, even though both components are mostly present in the same type of particles, it seems unlikely that preferential deposition alone could result in such a rise of the SEF. It therefore appears that $\mathrm{S}(\mathrm{VI})$ production reactions proceed in the stagnant air mass, and that the stabilization of the sulfate content then indicates the attainment of a steady-state between sulfate production and the sinks discussed previously. In-fog oxidation at an average rate of $0.9 \% \mathrm{~h}^{-1}$ (Table 2) with $\mathrm{P}_{\mathrm{SO}_{2}}=20$ $\mathrm{ppb}$ would produce 16 neq $\mathrm{m}^{-3} \mathrm{~S}(\mathrm{VI}) / \mathrm{h}$ of fog. This is not sufficient to explain the increases in the SEF of the daytime aerosol, especially since a large fraction of the sulfate that could be produced in fog is expected to be lost by deposition. Gas-phase oxidation of $\mathrm{SO}_{2}$ by radicals is expected to be unimportant because of the limited photochemical activity (reflected by the low $\mathrm{O}_{3}$ levels). Instead, the higher SEF values in the daytime aerosol than in the fog suggest that sulfate production mostly occurs in the haze droplets forming at high humidities. This could be expected because of the higher catalyst concentrations in haze droplets, and because both temperatures and $\mathrm{SO}_{2}(\mathrm{~g})$ concentrations usually peak in the afternoon. Oxidation of S(IV) in haze droplets should proceed along similar pathways as for fog droplets, and has been observed to proceed rapidly under controlled conditions (Matteson et al., 1969; Crump et al., 1983).

\subsection{Fogwater acidity}

Extreme acidity in fogwater, as has been documented in the Los Angeles area, may pose specific environmental problems because of the potential for injury to materials, vegetation (Scherbatskoy and Klein, 1983), and human health (Hoffmann, 1984). Sulfuric acid and nitric acid (which are the main strong acids present) can be emitted into the atmosphere as primary pollutants, or alternatively be produced in situ (Calvert, 1984). Alkaline components in the atmosphere will titrate free acidity. Gaseous ammonia, which is the most important alkaline component in the Valley, reacts with $\mathrm{H}_{2} \mathrm{SO}_{4}$ and $\mathrm{HNO}_{3}$ at high humidities to form concentrated ammonium salt droplets (Stelson, 1982). Dissolution of $\mathrm{SO}_{2}(\mathrm{~g})$ in the aquated aerosol leads to S(IV), which can then be oxidized to S(VI) as discussed in the previous section. Alternatively, S(IV) can be stabilized in the lower oxidation state by complexation with carbonyl compounds (Munger et al., 1984). The production of one molar unit of $\mathrm{S}(\mathrm{VI})$ releases one to two molar units of $\mathrm{H}^{+}$; formation of $\mathrm{S}(\mathrm{IV})$ adducts also produces $\mathrm{H}^{+}$ (Jacob and Hoffmann, 1983). The resulting input of acidity can be subsequently titrated by absorption of $\mathrm{NH}_{3}(\mathrm{~g})$ in the droplet. Therefore, the acidity of liquid water in an air mass under high sulfate and nitrate conditions is limited by the availability of $\mathrm{NH}_{3}(\mathrm{~g})$ (and other alkaline components) to neutralize the strong acids present. This has previously been observed for rainwater in the north-central United States (Munger, 1982).

In Los Angeles, where $\mathrm{NH}_{3}$ emissions are relatively low (Russell et al., 1983), extremely high acidities are frequently found in the fogwater. In the Bakersfield fogwater, nitrate and sulfate concentrations are comparable to those in Los Angeles, but high acidities are much less common (Fig. 7). This is because ammonium concentrations are

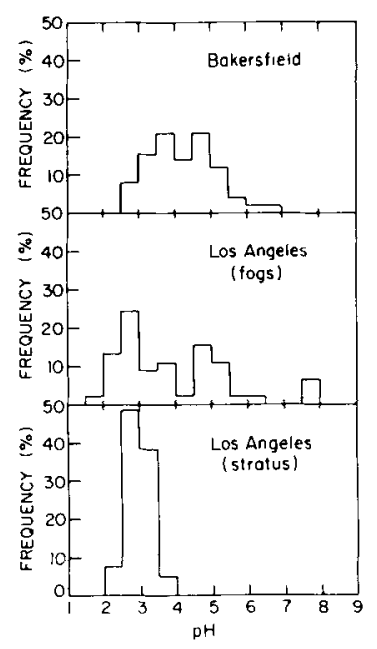

Fig. 7. $\mathrm{pH}$ frequency distribution for $n=108$ fogwater samples collected at Bakersfield during the period 30 December 1982-15 January 1983. Results are compared with those obtained in the Los Angeles basin for fogs $(n=45)$ and stratus clouds $(n=156)$ (this laboratory, unpublished results, 1981-1983). 


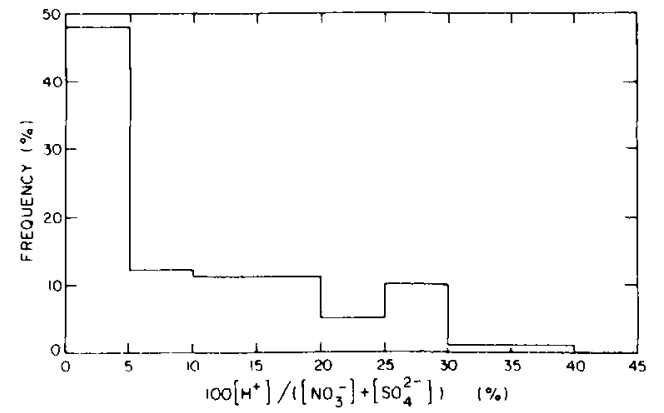

Fig. 8. Frequency distribution of the non-neutralized fraction of the acidity, as expressed by $\left|\mathrm{H}^{+}\right| /\left(\left|\mathrm{NO}_{3}^{-}\right|+\right.$ $\left|\mathrm{SO}_{4}^{2-1}\right|$ ), for $n=108$ fogwater samples collected at Bakersfield during the period 30 December 1982-15 January 1983.

considerably higher than in Los Angeles. A few samples at Bakersfield also had high concentrations of $\mathrm{Ca}^{2+}$, indicating an alternative neutralization pathway by scavenging of alkaline dust.

Fig. 8 shows the fraction of non-neutralized acidic anions in our fog samples. In almost half of the samples, over $95 \%$ of the acidity was neutralized. At the same time, very low concentrations of gaseous ammonia were observed throughout the 17 days (Fig. 3). Most of the fogwater samples had $\mathrm{pH}$ values below 5 , which suggests an absence of ammonia in the atmosphere from chemical equilibrium considerations. Ostensibly, the acidities present were sufficient to totally exhaust ammonia from the gas phase, and production of additional acidity resulted in a $\mathrm{pH}$ drop.

\section{Conclusion}

High ionic concentrations in the fogwater were observed at Bakersfield, California over the course of two stagnation episodes. The main contributors to the ionic loading of the fogwater were $\mathrm{NH}_{4}^{+}$, $\mathrm{NO}_{3}^{-}$, and $\mathrm{SO}_{4}^{2-}$; this can be attributed to agricultural activity and oil recovery processes. Droplet growth was found to strongly influence the observed concentrations. Comparison of ionic load- ings in the fogwater with those in the aerosol of the previous afternoon indicated that a sizable fraction of the aerosol was scavenged by the fog droplets. Fogwater ionic loadings decreased considerably over the course of the fog, and this was attributed to deposition of the large droplets on surfaces. In this manner, it was observed that a large fraction of the pollutants scavenged in the fog could be removed from the atmosphere. Deposition of fog droplets proceeds much more rapidly than deposition of the haze particles present at the high humidities between fog events, so that the occurrence of fog could slow down or limit the accumulation of particulate matter in a stagnant air mass.

Evolution of the sulfate content over the 17-day sampling period indicated an important increase of the sulfate fraction in the aerosol during stagnation episodes, but no statistical evidence for S(IV) oxidation in the fogwater was found. Most of the sulfate appeared to be produced in the daytime haze droplets. Preferential deposition of components other than sulfate could also partly explain the increase in the sulfate fraction.

High concentrations of acidic anions were present in the fogwater, but most of the acidity was neutralized by ammonia. In most cases, the neutralization of acidic components totally depleted $\mathrm{NH}_{3}$ from the atmosphere; although the excess of acidity was usually not enough to lead to highly acidic conditions, $8 \%$ of the samples had $\mathrm{pH}$ values below 3 .

\section{Acknowledgements}

This research was funded by the California Air Resources Board (CARB). We thank the staff of the CARB for their help and cooperation relating to our use of their facility at Bakersfield. We also acknowledge gratefully the CARB and the Western Oil and Gas Association for letting us use their data in this paper. Discussions with A. G. Russell were most helpful in the interpretation of some of the data.

\section{REFERENCES}

Brown, R. and Roach, W. T. 1976. The physics of radiation fog (II). A numerical study. $Q$. J. $R$. Meteorol. Soc. 102, 335-354.
Brown, R. 1980. A numerical study of radiation fog with an explicit formulation of the microphysics. Q.J. $R$. Meteorol. Soc. 106, 781-802. 
California Air Resources Board 1982. Emission Inventory 1979, Stationary Source Control Division, Emission Inventory Branch, Sacramento, California.

Calvert, J. G. (ed.) 1984. Acid precipitation. Butterworth Publications, Boston.

Cass, G. R. 1979. On the relationship between sulfate air quality and visibility with examples in Los Angeles. Atmos. Environ. 13, 1069-1084.

Cass, G. R. 1981. Sulfate air quality control strategy design. Atmos. Environ. 15, 1227-1249.

Chylek, K. P. 1978. Extinction and liquid water content of fogs and clouds. J. Atmos. Sci. 35, 296-300.

Commins, B. T. and Waller, R. E. 1967. Observations from a ten-year study of pollution at a site in the city of London. Atmos. Environ. 1, 49-68.

Crump, J. G., Flagan, R. C. and Seinfeld, J. H. 1983. An experimental study of the oxidation of sulfur dioxide in aqueous manganese sulfate aerosols. Atmos. Environ. 17, 1277-1289.

Duckworth, S. and Crowe, D. 1979. Sulfur dioxide and sulfate trends, Bakersfield, 1977-1978. Technical Services Division, California Air Resources Board, Sacramento, California.

Gerber, H. E. 1981. Microstructure of a radiation fog. $J$. Atmos. Sci. 38, 454-458.

Goodeve, C. F. 1936. Discussion in "Sulphuric acid as a disperse phase in town air". Trans. Faraday Soc. 32 , 1201-1202.

Hegg, D. A. and Hobbs, P. V. 1981. Cloud water chemistry and the production of sulfates in clouds. Atmos. Environ. 15, 1597-1604.

Hegg, D. A. and Hobbs, P. V. 1982. Measurements of sulfate production in natural clouds. Atmos. Environ. $16,2663-2668$.

Hegg, D. A. 1983. The sources of sulfate in precipitation (1). Parameterization scheme and physical sensitivities. J. Geophys. Res. 88, 1369-1374.

Heisler, S. and Baskett, R. 1981. Particle sampling and analysis in the California San Joaquin Valley. Research report CARB-RR-81-14, December 1981, available from Environmental Research and Technology, Westlake Village, California.

Hering. S. V. and Blumenthal, D. L. 1983. Field comparison of fog/cloud water collectors: preliminary results. Proceedings, Air Pollution Control Association Specialty Conference on the Meteorology of Acid Deposition, Hartford, Connecticut, $17 \mathrm{Oc}$ tober 1983. Published by the Air Pollution Control Association, Pittsburgh.

Hoffmann, M. R. and Jacob, D. J. 1984. Kinetics and mechanisms of the catalytic autoxidation of dissolved sulfur dioxide in aqueous solution: an application to night-time fogwater chemistry. In Acid precipitafion (ed. J. G. Calvert). Boston: Butterworth Publications, 101-172.

Hoffmann, M. R. 1984. Comment on acid fog. Environ. Sci. Technol. 18,61-64.

Holets, S. and Swanson, R. N. 1981. High-inversion fog episodes in central California. J. Appl. Meteorol. 20 , 890-899.
Houghton, H. G. 1955. On the chemical composition of fog and cloud water. J. Meteorol. 12, 355-357.

Jacob, D. J. and Hoffmann, M. R. 1983. A dynamic model for the production of $\mathrm{H}^{+}, \mathrm{NO}_{3}^{-}$, and $\mathrm{SO}_{4}^{2-}$ in urban fog. J. Geophys. Res. 88, 6611-6621.

Jacob, D. J., Wang, R.-F. T. and Flagan, R. C. 1984. Fogwater collector design and characterization. Environ. Sci. Technol. 18, (in press).

Lazrus, A. L., Baynton, H. W. and Lodge, J. P. 1970. Trace constituents in oceanic cloud water and their origin. Tellus 22, 106-114.

Mader, P. P., Hamming, W. J. and Bellin, A. 1949. Determination of small amounts of sulfuric acid in the atmosphere. Anal. Chem. 22, 1181-1183.

Martin, L. R. 1984. Kinetic studies of sulfite oxidation in aqueous solution. In Acid precipitation (ed. J. G. Calvert), Boston: Butterworth Publications, 63-100.

Matteson, M. J., Stober, W. and Luther, H. 1969. Kinetics of the oxidation of sulfur dioxide by aerosols of manganese sulfate. I.\& E. C. Fund. 8, 677-686.

Mrose, H. 1966. Measurements of $\mathrm{pH}$, and chemical analyses of rain-, snow-, and fog-water. Tellus 18 , 266-270.

Muller, J. 1982. Rules in atmospheric behaviour of particulate substances. GAF-conference, Bologna, 14-17 September 1982, Fraunhofer Ges., Grafschaft/ Schmallenberg, F. R. Germany.

Munger, J. W. 1982. Chemistry of atmospheric precipitation in the north central United States: influence of sulfate, nitrate, ammonia, and calcareous soil particulates. Atmos. Environ. 16, 1633-1645.

Munger, J. W., Jacob, D. J., Waldman, J. M. and Hoffmann, M. R. 1983. Fogwater chemistry in an urban atmosphere. J. Geophys. Res. 88, 5109-5123.

Munger, J. W., Jacob, D. J. and Hoffmann, M. R. 1984. The occurrence of bisulfite aldehyde addition products in fog-and cloudwater. J. Atmos. Chem. (in press).

National Oceanic and Atmospheric Administration 1983. Local climatological data (monthly summary) for Bakersfield, CA, Kern County air terminal, December 1982 and January 1983, Published by US Dept. of Commerce, National Climatic Data Center, Asheville, North Carolina, USA.

Okita, T. 1968. Concentration of sulfate and other inorganic materials in fog and cloud water and in aerosol. J. Meteorol. Soc. Japan 46, 120-126.

Petrenchuk, O. P. and Drozdova, V. M. 1966. On the chemical composition of cloudwater. Tellus 18 , 260-286.

Pruppacher, H. R. and Klett, J. D. 1978. Microphysics of clouds and precipitation. Amsterdam: Reidel, 418421.

Reible, D. D., Shair, F. H., Smith, T. B. and Lehrman. D. E. 1984. The origin and fate of air pollutants in California's San Joaquin Valley (I). Winter. Atmos. Environ. (in press).

Roach, W. T. 1976. On some quasi-periodic oscillations observed during a field investigation of radiation fog, Q.J.R. Meteorol. Soc. 102, 355-359.

Russell, A. G. 1983. Analysis of oxalic acid impregnated 
filters for ammonia determination. Environmental Quality Lab open file report 83-1, California Institute of Technology, Pasadena, California.

Russell, A. G.. McRae, G. J. and Cass. G. R. 1983. Mathematical modeling of the formation and transport of ammonium nitrate aerosol. Atmos. Environ. 17, 949-964.

Scherbatskoy, T. and Klein, R. M. 1983. Response of spruce and birch foliage to leaching by acidic mists. $J$. Environ. Qual. 12, 189-195.

Schwariz, S. E. and White, W. H. 1981. Solubility equilibria of the nitrogen oxides and oxyacids in dilute aqueous solution. Adv. Environ. Sci. Eng. 4, 1-45.

Schwartz, S. E., Newman, L., Hegg. D. A. and Hobbs, P. V. 1983. Measurements of sulfate production in natural clouds (discussion). Atmos. Environ. 17, 2629-2633.

Smith, T. B., Lehrman, D. E., Reible, D. D. and Shair, F. H. 1981. The origin and fate of airborne pollutants within the San Joaquin Valley. Final report to the California Air Resources Board, Sacramento, California.

Stelson, A. W. 1982. Thermodynamics of aqueous atmospheric aerosols. Ph.D. thesis, California Institute of Technology, Pasadena, California.

Waldman, J. M., Munger, J. W., Jacob, D. J., Flagan. R. C., Morgan, J. J. and Hoffmann, M. R. 1982. Chemical composition of acid fog. Science 218 . 677-680. 